Sharif University of Technology
Scientia Iranica
SCIENTIA
IRAN I CA
Transactions A: Civil Engineering
www.scientiairanica.com

\title{
Parametric study and computation of seismic performance factors of braced shear panels
}

\author{
A. Akbari Hamed ${ }^{a, *}$ and M. Mofid ${ }^{\mathrm{b}}$ \\ a. Department of Civil Engineering, Sahand University of Technology, Tabriz, Iran. \\ b. Department of Civil Engineering, Sharif University of Technology, Tehran, Iran. \\ Received 18 October 2014; received in revised form 8 June 2015; accepted 25 July 2015
}

\author{
KEYWORDS \\ Braced steel shear \\ panel; \\ Parametric study; \\ Over-strength factor; \\ Deflection \\ amplification factor; \\ Response modification \\ factor; \\ Strip model; \\ Modified strip model.
}

\begin{abstract}
By locating a steel shear panel on the intersection point of the X-braces, concentrically or eccentrically braced shear panel (CBFSP or EBFSP) is formed. In this paper, to perform parametric study, 1-story CBFSP and EBFSP models with span length greater or less than height are considered. Using linear static analyses, the effects of size and location of the shear panel on the lateral stiffness of the frame with respect to the moment resisting frame with the same member sections are investigated. Next, for 1- and 3-story models, maximum displacement, along with base shear, and the ratio between the dissipated energy and input energy are examined under 4 ground motion records. Behavior of the truss elements in cross-strip model for nonlinear dynamic analyses is validated based on a performed experimental program. The findings show that the optimum state is achieved by decreasing size of the shear panel and situating it in the middle of the frame or, to some extent, upper. Furthermore, in this study, tentative values of the over-strength, deflection amplification, and response modification factors, which are estimated by pushover curves, are proposed. Using linear regression, an equation is obtained for estimation of the fundamental period of CBFSP and EBFSP.
\end{abstract}

(C) 2016 Sharif University of Technology. All rights reserved.

\section{Introduction}

Designing the buildings in such a way to act elastically in most severe earthquakes is uneconomical. Due to this fact, some certain portions of the buildings are designed to act as plastic fuses to direct the material nonlinearity toward those predetermined parts. Consequently, the yielded regions dissipate the earthquake input energy by their cyclic hysteretic behavior and the remaining members stay elastic. Based on the numerical and experimental studies, Steel Plate Shear Walls (SPSW) are one of the accepted yielding devices, which are used for tall buildings [1-3]. Using postbuckling strength of unstiffened SPSWs causes large

*. Corresponding author. Tel.: +98 4133459396 E-mail address: akbarihamed.a@sut.ac.ir (A. Akbari Hamed) distributed loads induce on the surrounding main structural members. One of the solutions, which have been proposed to overcome the mentioned undesirable effect, is reduction of contact between the steel plate and the beams along with columns. In this regard, beamattached SPSWs [4,5], SPSWs with tension-bracing [6], and discontinuous connection of the plate to boundary frame [7] have been introduced. The recommended system of De Matteis et al. [8], on this subject, was a combination of concentrically braced frame and a steel shear panel in the middle intersection point of the X-braces. In braced steel shear panel systems, beside separation of the shear panel from the main members, there is a possibility of changing the panel's height for early yielding of it in conjunction with allocation of more area for openings.

To increase confidence of the engineers in order to expand the usage of CBFSPs and EBFSPs, a 
comprehensive research on design and seismic behavior of these new structural systems, along with a comparative experimental program of stiffened and unstiffened steel shear panels, has been performed [9]. This paper presents the parametric study and quantification of seismic performance factors for both types of the braced steel shear panels. In a way similar to Tajammolian and Mofid [10], for recognition of the optimum size and location of the shear panel, 404 linear static analyses along with 96 nonlinear dynamic analyses were performed. In linear analyses, lateral stiffness of the 1-story CBFSPs and EBFSPs was compared with the corresponding values of the moment resisting frames with the same member sections. For assessment of the relationship between the dimensional ratios of Horizontal Boundary Element (HBE) to span length along with Vertical Boundary Element (VBE) to story height, different sizes of shear panels were considered. Following, the optimal sizes were located at different positions and they were analyzed linearly. Subsequently, the nonlinear behavior of the selected sizes and locations of shear panel were assessed under 4 ground motion records. At this step, for evaluation of the building models, maximum displacement, maximum base shear, and dissipated energy were selected as criteria. It should be noted that in this study, the nonlinear behavior of the truss elements for strip modeling of the shear panels was validated by the hysteretic curve of the tested specimen. Finally, the overall behavior of 3-story models was investigated by nonlinear time history analyses.

Based on common codes, there are three seismic performance factors which are used for designing the structures. These factors include response modification factor, over-strength factor, and deflection amplification factor. Therefore, in this paper, tentative values for these factors are estimated to coordinate the design of CBFSPs and EBFSPs with the available codes. To this aim, 1-, 3-, 6-, and 9-story CBFSPs and EBFSPs were analyzed using nonlinear static procedure (i.e., pushover analysis). Next, by the resulted pushover curves, all of the required parameters were calculated. In this study, ductility reduction factor and, consequently, response modification factor were obtained using four different suggested equations as: 1) Newmark-Hall, 2) Nassar-Krawinkler, 3) Fajfar, and 4) Riddell-Hidalgo-Cruz. Furthermore, using linear regression, an equation was obtained for approximate estimation of the fundamental period.

\section{Parametric study}

\subsection{Finite element models}

The CBFSP and EBFSP models of this study were designed according to the failure mode control method $[9,11,12]$. The considered desired collapse mechanism for CBFSP is the yielding of the shear panels and then development of plastic hinges in the beams and base of the first story's columns. For EBFSP, member hierarchy criteria are similar to those for CBFSP, except that in this case, shear links should be yielded instead of plastic hinges development in the beams. Two types of 1-story models were considered, in which the ratio between the span length $(L)$ and the story height $(H)$ was greater and less than one. For $L / H>1$, the respective values of the span length and story height were $4 \mathrm{~m}$ and $2.8 \mathrm{~m}$. In the case of models with $L / H<1$, the aforementioned values in the previous sentence were assigned to the span length and story height, inversely. Moreover, 3 -story models were discussed just with $L / H>1$ and the same values. The steel shear panel, along with all of the remaining members, were modeled using the tension-only strip concept with pinned-ends and frame members, respectively. Moreover, all of the connections were moment connections, except the connectivity of braces and boundary elements, in which pin-connections were used (Figure 1). A uniformly distributed load of intensity $1000 \mathrm{~kg} / \mathrm{m}$ was applied to the beam of the models. The assigned member sections for the models are listed in Table 1.

For nonlinear dynamic analysis, the same models with regards to material nonlinearity were considered. At this step, taking into account the cyclic behavior of the shear panel owing to ground motion records, the cross-strip concept was used (Figure 2). To evaluate the pure effect of size and location of steel shear panel, only material nonlinearity of the tension-only strips was considered and all of the other members acted elastically. For the considered models, a constant damping ratio of $2 \%$ was assigned to all modes. In this study, due to the large number of models, Fast Nonlinear Analysis

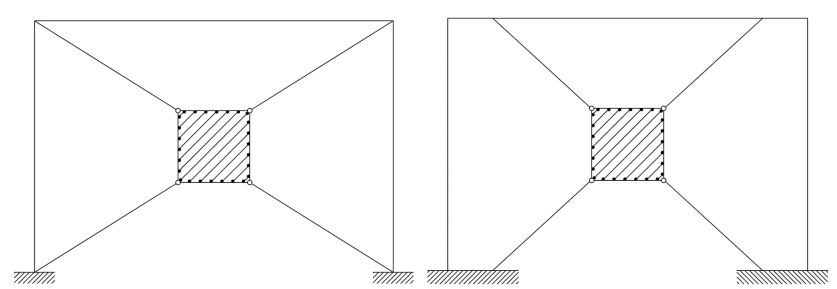

Figure 1. Finite element models of CBFSP and EBFSP for linear static analysis.

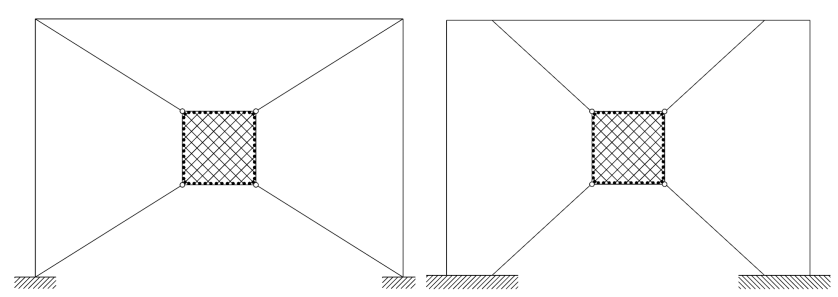

Figure 2. Finite element models of CBFSP and EBFSP for nonlinear dynamic analysis. 
Table 1. Member sections of the building models.

\begin{tabular}{|c|c|c|c|c|c|c|c|}
\hline & & & \multicolumn{5}{|c|}{ Member section } \\
\hline & & & Beam & Column & Brace & $\begin{array}{c}\text { Shear } \\
\text { link }\end{array}$ & $\begin{array}{c}\text { Boundary } \\
\text { element }\end{array}$ \\
\hline \multirow{4}{*}{ 1-story } & \multirow{2}{*}{$L / H>1$} & CBFSP & IPE140 & IPE270 & IPE240 & - & IPE140 \\
\hline & & EBFSP & IPE140 & IPE270 & IPE240 & IPE100 & IPE140 \\
\hline & \multirow{2}{*}{$L / H<1$} & CBFSP & IPE200 & IPE270 & IPE240 & - & IPE140 \\
\hline & & EBFSP & IPE220 & IPE270 & IPE240 & IPE160 & IPE140 \\
\hline \multirow{2}{*}{3 -story } & \multirow{2}{*}{$L / H>1$} & CBFSP & IPE180 & IPE330 & IPE240 & - & IPE140 \\
\hline & & EBFSP & IPE180 & IPE330 & IPE240 & IPE160 & IPE140 \\
\hline
\end{tabular}

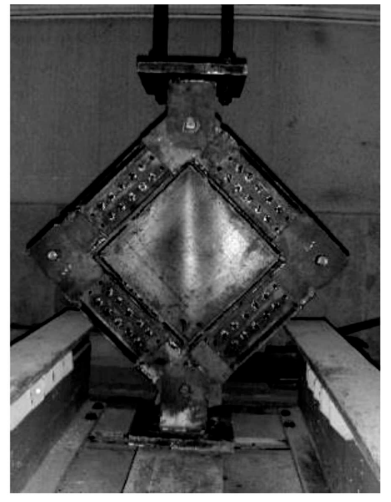

(a)

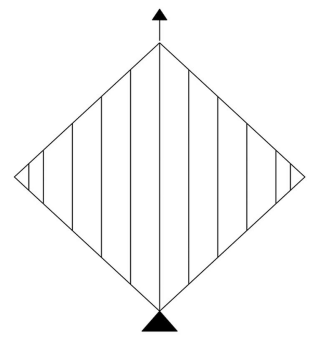

(c)

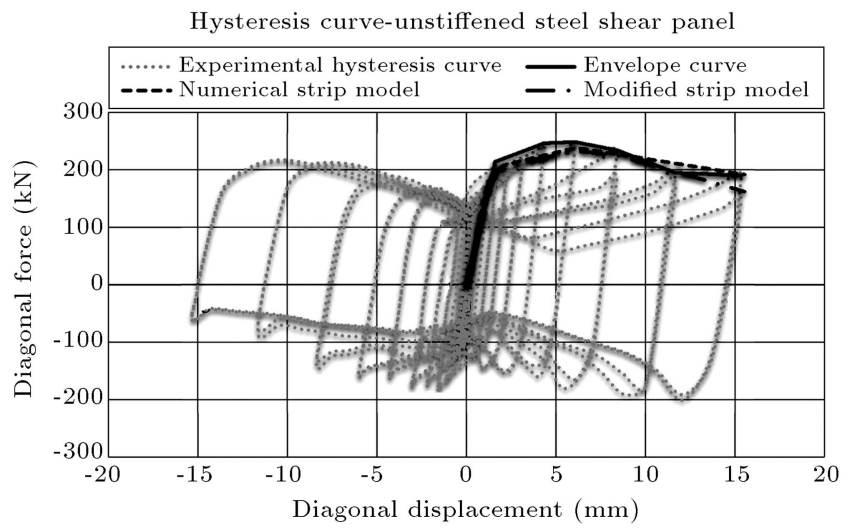

(b)

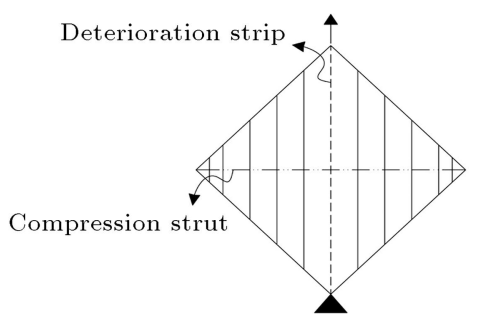

(d)

Figure 3. (a) Steel shear panel specimen. (b) Validation of strip models with experimental hysteretic curve. (c) Simple strip model. (d) Modified strip model.

(FNA), which is a modal time history analysis, was used for nonlinear dynamic analysis of the considered models. In this procedure, equilibrium equation is as follows:

$$
M \ddot{u}(t)+C \dot{u}(t)+K u(t)+R_{N L}(t)=R(t),
$$

where, $M$ is mass matrix; $C$, damping matrix; $K$, elastic stiffness matrix; $R_{N L}$, nonlinear-object force vector; $R$, external dynamic force vector; $\ddot{u}$, acceleration vector; $\dot{u}$, velocity vector; and $u$, displacement vector. It should be noted that separation of $R_{N L}$ from the elastic stiffness matrix and the damped equations of motion is the efficiency of this formulation [13]. For dynamic analysis, as it is required for FNA analysis, the strips were modeled using multilinear plastic links.
In this study, a full scale unstiffened steel shear panel specimen was subjected to a quasi-static cyclic loading history based on FEMA 461, along its diagonal direction (Figure 3(a)) [14]. For accurate modeling of nonlinear behavior of the strips, the obtained pushover curves of the finite element models of the tested specimen were validated using the envelope curve of the experimental hysteretic curve (Figure 3(b)). As shown in Figure 3(c) and (d), two finite element models of the specimen were created using simple strip concept along with the modified strip concept [15]. For this purpose, truss elements along with frame elements were used for modeling of strips and boundary elements, respectively. All of the members were connected together by pinconnections and then, with regards to the accomplished 
experimental program, pushover analyses were performed to reach the diagonal target displacement of $15 \mathrm{~mm}$. In simple strip concept, all of the strips has the same nonlinear behavior. Whereas, in the modified strip concept, there are two additional strips including the deterioration strip and the compression strut. In both of the strip models, the assigned nonlinear property for the strips was a tri-linear behavior with $3 \%$ strain-hardening (i.e., to reach $1.18 F_{y}$ at $6 \varepsilon_{y}$ ) along with $2 \%$ softening slopes (Figure 4(a)). Moreover, the compression strut had elastic-perfectly plastic behavior (Figure 4(b)) and nonlinear behavior of the deterioration strip was assigned considering the performed test in which tearing of the corners of the panel began at a diagonal displacement of $8.527 \mathrm{~mm}$. In nonlinear behavior of the deterioration strip, yielding plateau continued to a displacement which was chosen in such a way that at $8.527 \mathrm{~mm}$ of the resulted pushover curve of the modified strip model, a strength degradation

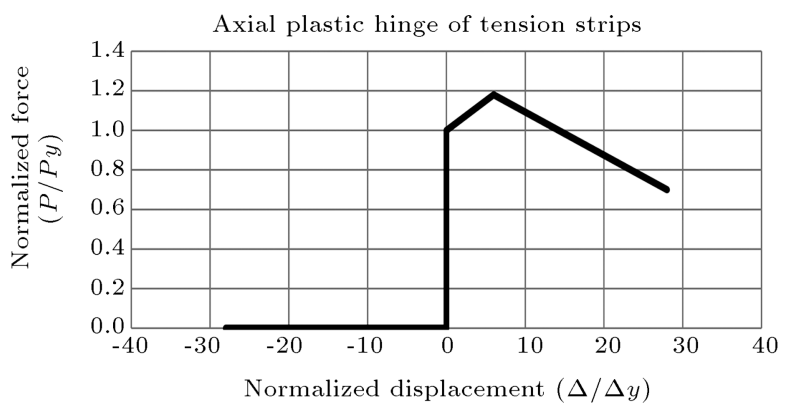

(a)

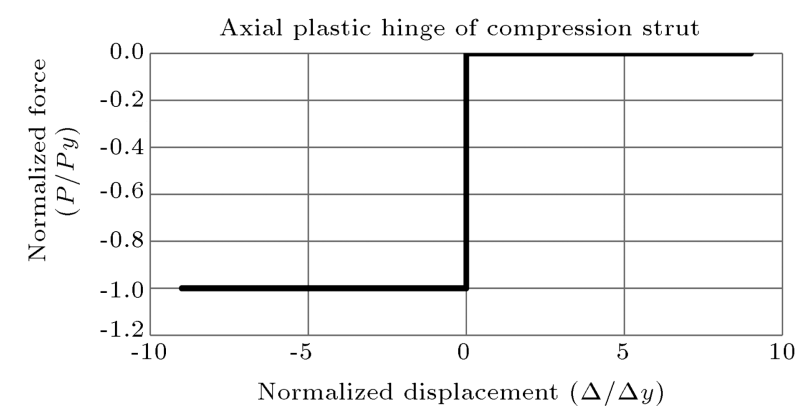

(b)

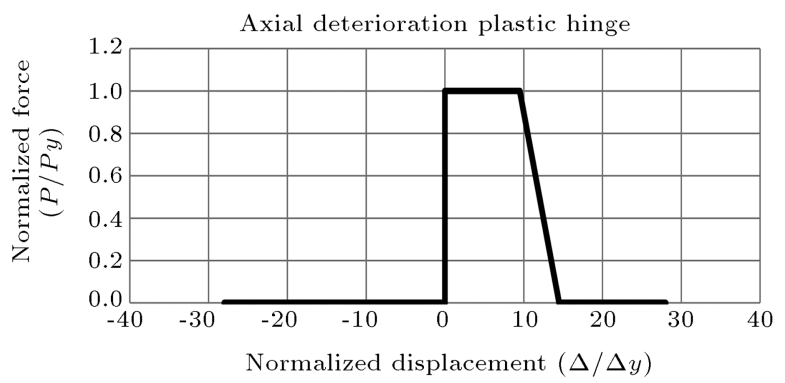

(c)

Figure 4. The considered behavior for axial plastic hinge of (a) tension strips, (b) compression strut, and (c) deterioration hinge. was observed. Subsequently, due to that tearing of the specimen's corners extended to $50 \mathrm{~mm}$, which is approximately equal to the width of strips in the model $(57 \mathrm{~mm})$, strength of the deterioration strip decreased to zero by $20 \%$ of slope (Figure $4(\mathrm{c})$ ). It is worth noting that the hysteresis type for all of the plastic hinges was kinematic.

Regarding Figure 3(b), it is noticed that both the strip model and the modified strip model have an acceptable accuracy. In this study, shear panels of the CBFSP and EBFSP models were modeled by the strip model due to the simplicity in cross-strip models.

\subsection{Linear static analysis}

This section presents the results of linear static analyses to find the optimum size and location of shear panel in the CBFSPs and EBFSPs. This study was accomplished in two phases as follows:

1. Evaluation of the relationship between the HBE length and span length ratio along with the VBE length and story height ratio;

2. Assessment of the optimum position of the shear panel with the specified sizes of the first step.

To perform linear static analysis of the considered 1-story models, an equal lateral load was applied to both sides of the frame at the beam level. The changes of ratio between the lateral stiffness of the braced steel shear panels $\left(K^{\prime}\right)$ and the moment resisting frames, with the same member sections $(K)$, were chosen as a criterion to evaluate performance of the studied new structural systems. Considering Figure 5, Table 2 shows the various sizes and locations of the shear panel in the two phases of this study.

\subsubsection{Dimensional ratio of boundary elements to main members}

Using linear static analyses, the above listed combinations of different sizes of the shear panels were compared. As depicted in Figure 6, it is obvious that by increasing the shear panel size, the overall lateral stiffness of the frame decreases. In addition, up to $l=30 \% L$, high values of stiffness are achieved when the ratios of $\mathrm{HBE}$ to span length and VBE to story

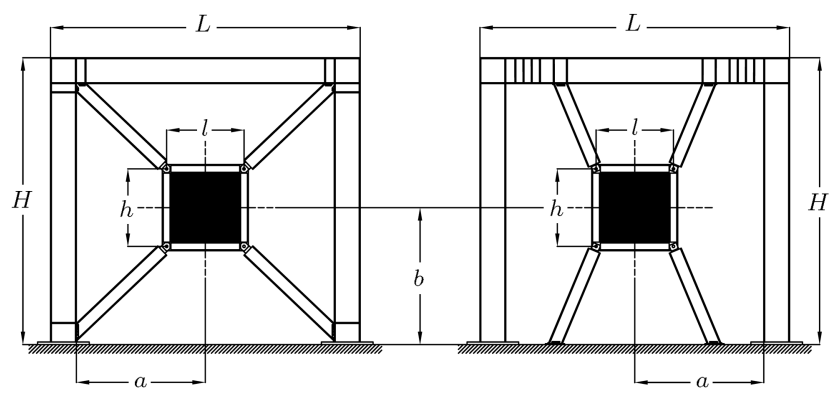

Figure 5. The geometrical parameters of CBFSP (left) and EBFSP (right). 
Table 2. The considered models for linear static analysis.

\begin{tabular}{|c|c|c|c|c|c|}
\hline & \multicolumn{2}{|c|}{ Panel-frame length ratio } & \multicolumn{3}{|c|}{ Size and location } \\
\hline & $l / L(\%)$ & $h / H(\%)$ & $\begin{array}{c}l / L-h / H \\
(\%)\end{array}$ & $a(\mathbf{m})$ & $b(\mathbf{m})$ \\
\hline \multirow{5}{*}{$\begin{array}{c}L / H>1 \\
(\mathrm{CBFSP} \& \mathrm{EBFSP})\end{array}$} & \multirow{5}{*}{$10-20-30-40-50$} & \multirow{5}{*}{$10-20-30-40-50-60$} & $10-10$ & $0.5-1-1.5-2$ & $0.3-0.8-1.4-2-2.5$ \\
\hline & & & $20-20$ & $0.5-1-1.5-2$ & $0.4-0.9-1.4-1.9-2.4$ \\
\hline & & & $30-30$ & $1-1.5-2$ & $0.6-1-1.4-1.8-2.2$ \\
\hline & & & $40-50$ & $1-1.5-2$ & $0.8-1.1-1.4-1.7-2$ \\
\hline & & & $50-60$ & $1.5-2$ & $1-1.2-1.4-1.6-1.8$ \\
\hline \multirow{5}{*}{$\begin{array}{c}L / H<1 \\
(\mathrm{CBFSP} \& \mathrm{EBFSP})\end{array}$} & \multirow{5}{*}{$10-20-30-40-50$} & \multirow{5}{*}{$10-20-30-40-50$} & $10-10$ & $0.5-1-1.4$ & $0.5-1-1.5-2-2.5-3-3.5$ \\
\hline & & & $20-20$ & $0.5-1-1.4$ & $1-1.5-2-2.5-3$ \\
\hline & & & $30-30$ & $0.5-1-1.4$ & $1-1.5-2-2.5-3$ \\
\hline & & & $40-30$ & $1-1.4$ & $1-1.5-2-2.5-3$ \\
\hline & & & $50-40$ & $1-1.4$ & $1-1.5-2-2.5-3$ \\
\hline
\end{tabular}
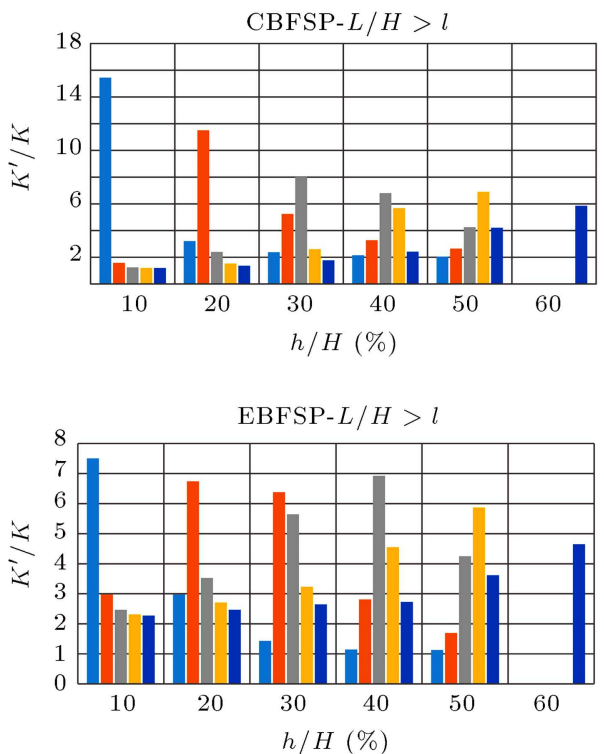

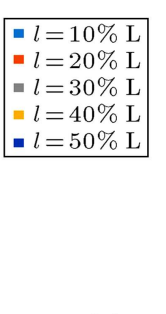

(a)
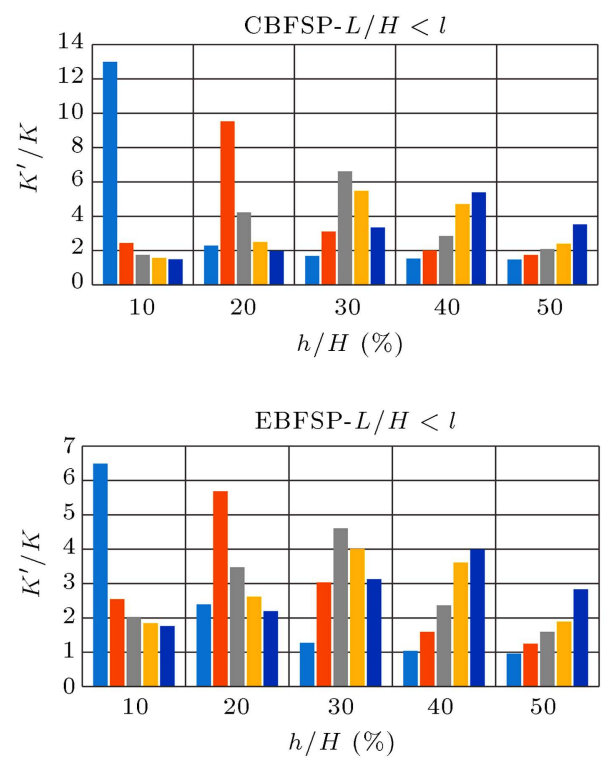

(b)

Figure 6. Comparison between lateral stiffness of various panels' dimension ratios: (a) CBFSP; and (b) EBFSP.

height are equal. Whereas, in larger sizes, there is a difference of $10 \%$ in scaling factors of the shear panel dimensions.

\subsubsection{Size and location}

Regarding the obtained results from Section 2.2.1, some of the assessed sizes of the shear panels have high stiffness with respect to the others in the same group of $\mathrm{HBE}$ to span length ratio. In this section, the selected sizes were located at different positions and the models were analyzed linearly and statically. The evaluated models are listed in the size and location header of Table 2. As depicted in Figure 5, due to geometrical symmetry of the frames, the shear panel's position in horizontal direction (i.e., a) changes from a column just to the middle of the frame. While $b$, where it shows the vertical position of the shear panel, changes from the bottom to the top of the frame. It should be noted that because of the existence of braces in these structural systems, both $a$ and $b$ were selected in such a way that the shear panel did not connect to the beam and columns. Moreover, due to dimensional limitations, as the size of the shear panel increased, the number of models which were investigated decreased. Figures 7 to 10 show the variation of the stiffness ratios for different locations of the shear panel in CBFSPs and EBFSPs. Based on the diagrams, it is concluded that vertical movement of the shear panel affects the lateral stiffness more than its horizontal movement, especially for $L / H<1$ frames. On the other hand, as the shear panel approaches the middle of the frame, the overall stiffness of the frame increases. Furthermore, in some 


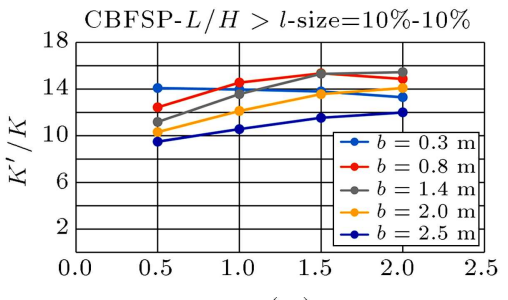

$a(\mathrm{~m})$
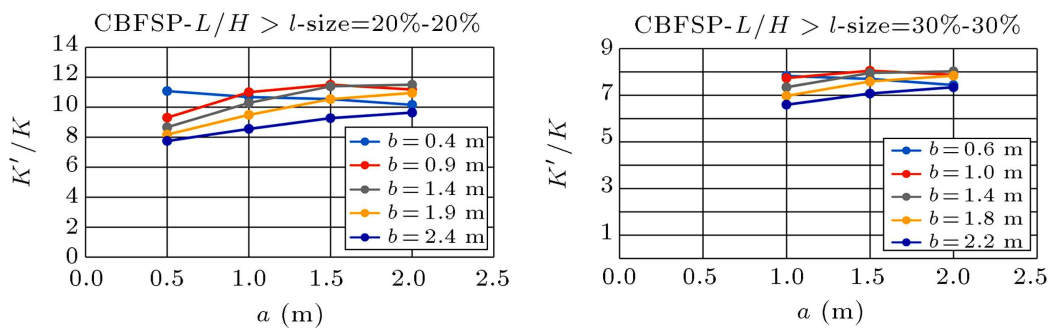
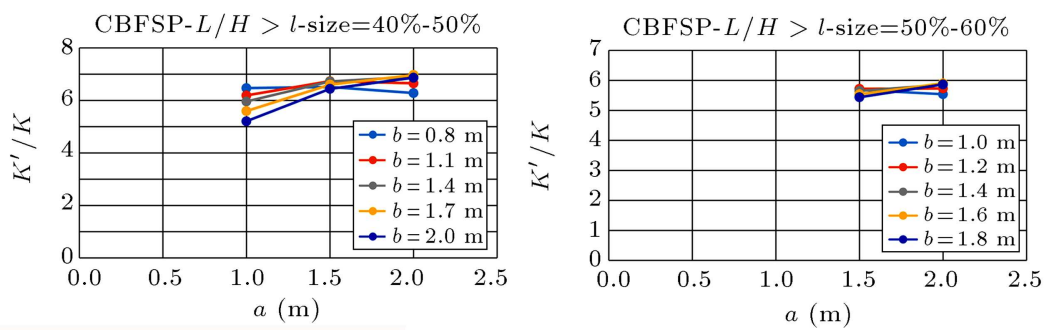

Figure 7. Comparison between lateral stiffness of various sizes and locations of shear panel in CBFSP with $L / H>1$.
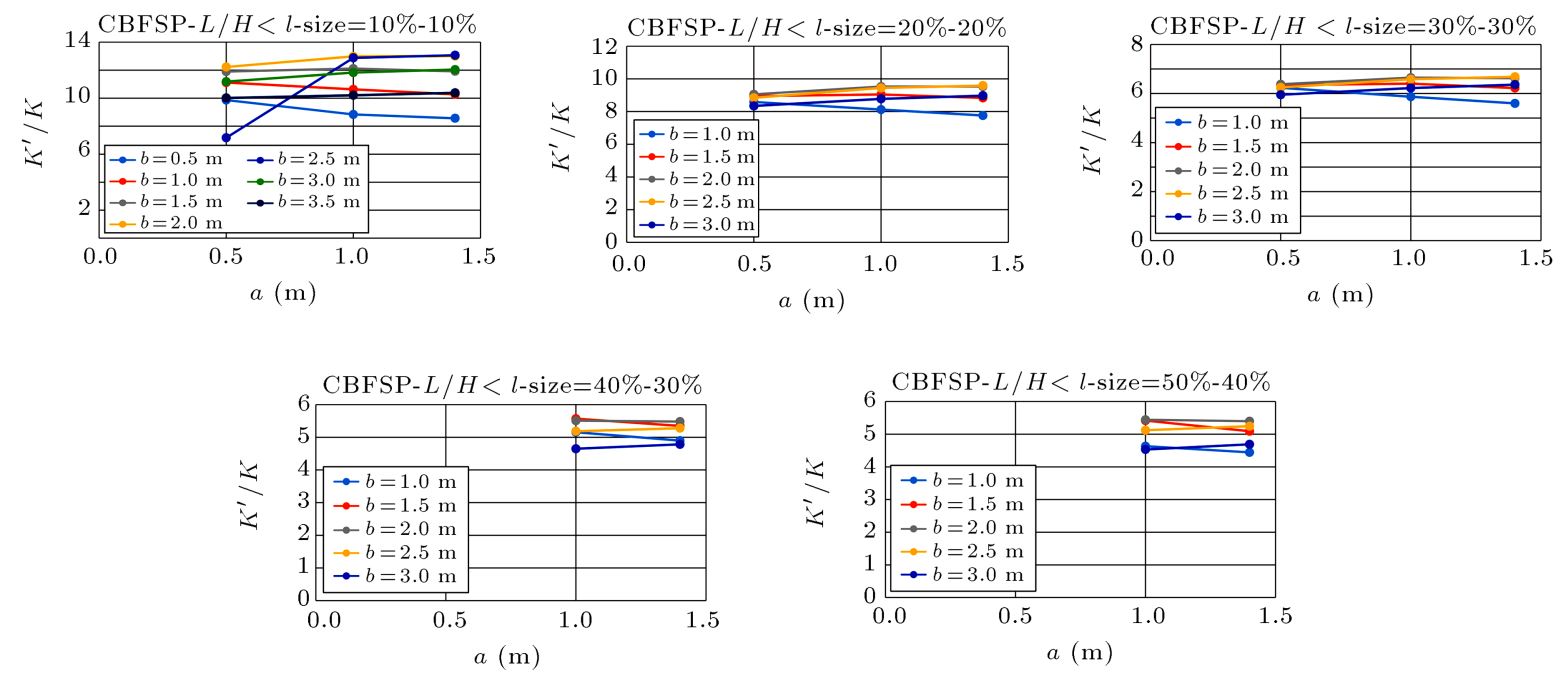

Figure 8. Comparison between lateral stiffness of various sizes and locations of shear panel in CBFSP with $L / H<1$.
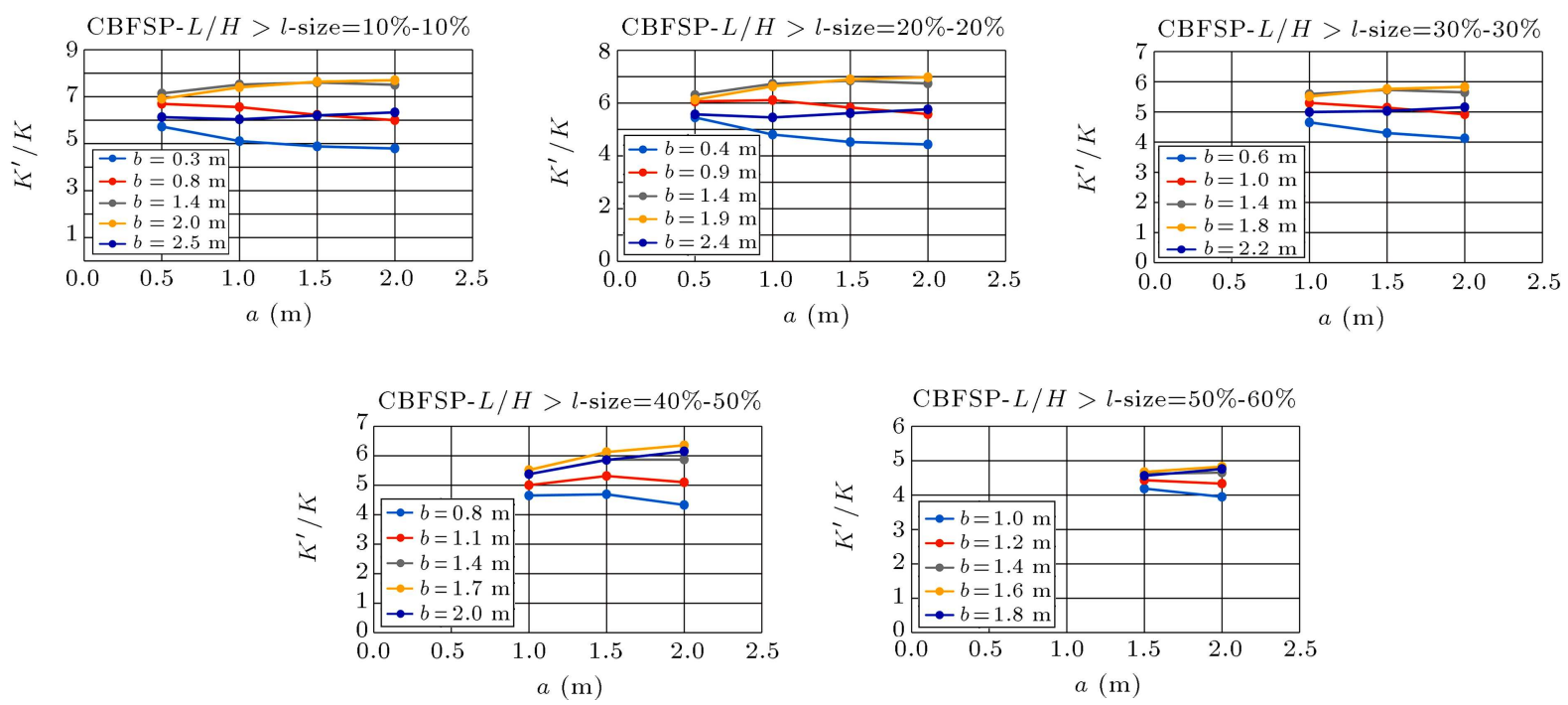

Figure 9. Comparison between lateral stiffness of various sizes and locations of shear panel in EBFSP with $L / H>1$. 

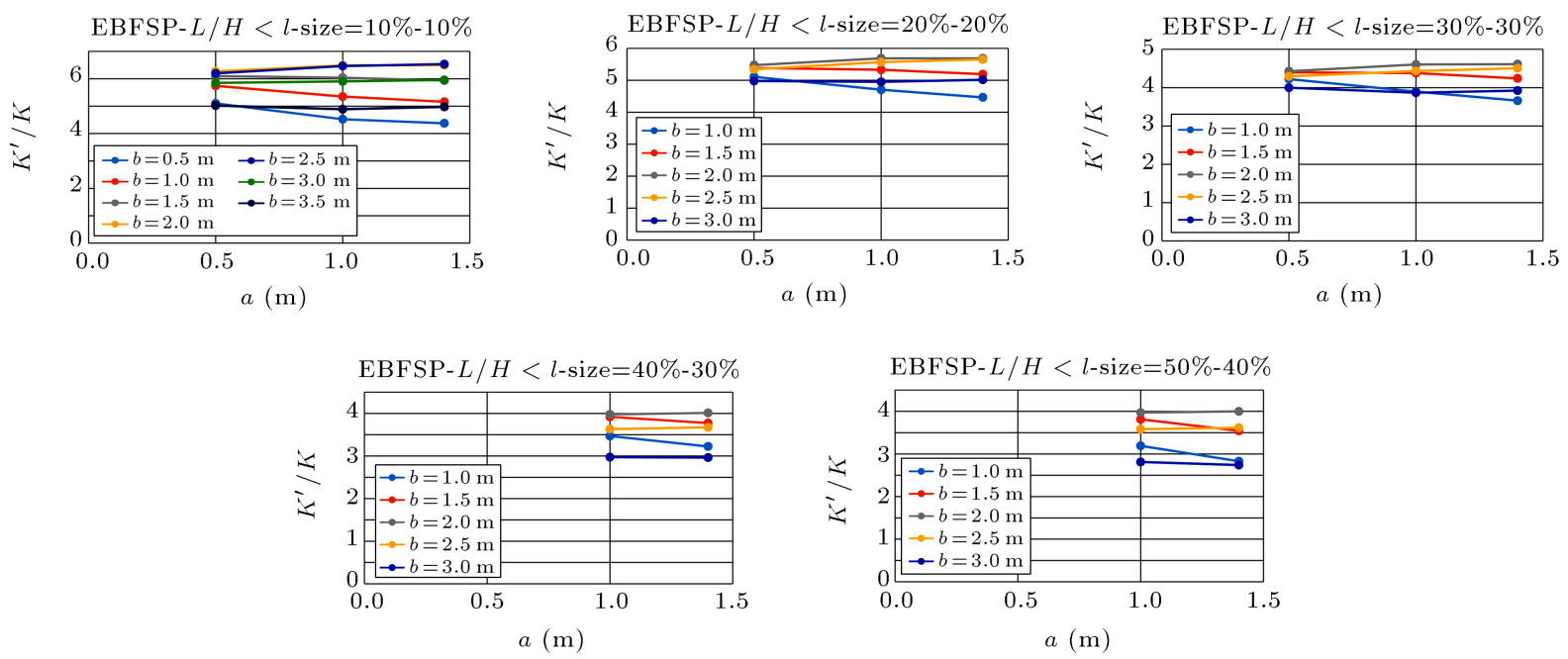

Figure 10. Comparison between lateral stiffness of various sizes and locations of shear panel in EBFSP with $L / H<1$.

cases, especially for EBFSPs, it is found that more stiffness is achieved when the shear panel moves to some upper point from the middle.

\subsection{Nonlinear dynamic analysis}

In this section, for investigation of nonlinear behavior of CBFSPs and EBFSPs, these two systems were analyzed under four ground motion records. The records were selected in such a way that the corresponding period values of their maximum pseudo-spectral acceleration $\left(T_{\max \text { PSA }}\right)$ had a quantity close to the average fundamental period of the models (Figure 11). Table 3 contains properties of the selected ground motion records. To perform nonlinear time history analyses,

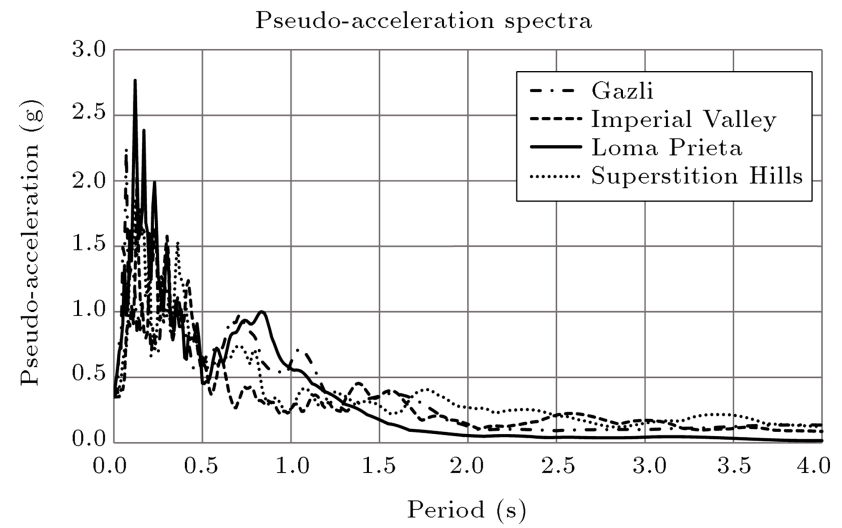

Figure 11. Pseudo-acceleration spectra of the selected ground motion records.
Peak Ground Acceleration (PGA) of the records was scaled to $0.35 \mathrm{~g}$. It can be mentioned that the records were scaled to a specific PGA to avoid failure of the designed models. In this phase of study, the ratios of maximum displacement and maximum base shear of the considered models with respect to the corresponding values of the moment resisting frames were selected as performance evaluation criteria.

It is known that the relationship between various types of energies in structures is determined by energy balance equation (Eq. (2)):

$$
E_{I}=E_{K}+E_{S}+E_{H}+E_{\xi}
$$

where, $E_{I}$ represents input energy; $E_{K}$, kinetic energy; $E_{S}$, elastic energy; $E_{H}$, hysteretic energy; and $E_{\xi}$, viscous damping energy. Dissipating the seismic input energy by nonlinear hysteretic behavior of yielding devices is desirable for structural engineers. Therefore, for evaluation of capability pertaining to the studied systems in absorbing seismic energy, the ratio of $E_{H}$ to $E_{I}$ will be assessed and reported in Sections 2.3.1 and 2.3.2.

\subsubsection{1-story buildings}

This section presents the results of nonlinear time history analyses of 1-story CBFSPs and EBFSPs. The size and location of the shear panel in the models are listed in Table 4. It should be noticed that these models are selected based on the results of linear static analyses.

Table 3. Ground motion records.

\begin{tabular}{cccccc}
\hline Earthquake name & Date & Station & Component & PGA $(\mathrm{g})$ & $\boldsymbol{T}_{(\max \text { PSA) }}(\mathbf{s})$ \\
\hline Gazli & $1976 / 05 / 17$ & Karakyr & 000 & 0.608 & 0.07 \\
Imperial Valley & $1979 / 10 / 15$ & El Centro Array \#13 & 230 & 0.139 & 0.13 \\
Loma Prieta & $1989 / 10 / 18$ & Waho & 000 & 0.398 & 0.12 \\
Superstition Hills & $1987 / 11 / 24$ & Wildlife liquefaction array & 090 & 0.132 & 0.14 \\
\hline
\end{tabular}


Table 4. The considered 1-story models for nonlinear dynamic analysis.

\begin{tabular}{|c|c|c|c|c|}
\hline & & Name & $\begin{array}{c}l / L-h / H \\
(\%)\end{array}$ & $\begin{array}{c}a-b \\
(\mathbf{m})\end{array}$ \\
\hline \multirow{10}{*}{$L / H>1$} & \multirow{5}{*}{ CBFSP } & SP1 & $10-10$ & $2-1.4$ \\
\hline & & SP2 & $20-20$ & $2-1.4$ \\
\hline & & SP3 & $30-30$ & $2-1.4$ \\
\hline & & $\mathrm{SP} 4$ & $40-50$ & $2-1.7$ \\
\hline & & SP5 & $50-60$ & $2-1.6$ \\
\hline & \multirow{5}{*}{ EBFSP } & SP6 & $10-10$ & $2-2$ \\
\hline & & SP7 & $20-20$ & $2-1.9$ \\
\hline & & SP8 & $30-30$ & $2-1.8$ \\
\hline & & SP9 & $40-50$ & $2-1.7$ \\
\hline & & SP10 & $50-60$ & $2-1.6$ \\
\hline \multirow{10}{*}{$L / H<1$} & \multirow{5}{*}{ CBFSP } & SP11 & $10-10$ & $1.4-2.5$ \\
\hline & & SP12 & $20-20$ & $1.4-2.5$ \\
\hline & & SP13 & $30-30$ & $1.4-2.5$ \\
\hline & & SP14 & $40-30$ & $1.4-2$ \\
\hline & & SP15 & $50-40$ & $1.4-2$ \\
\hline & \multirow{5}{*}{ EBFSP } & SP16 & $10-10$ & $1.4-2.5$ \\
\hline & & SP17 & $20-20$ & $1.4-2$ \\
\hline & & SP18 & $30-30$ & $1.4-2$ \\
\hline & & SP19 & $40-30$ & $1.4-2$ \\
\hline & & SP20 & $50-40$ & $1.4-2$ \\
\hline
\end{tabular}

As depicted in Figures 12 and 13, the obtained results from nonlinear dynamic analyses do confirm the conclusions for linear static analyses. Therefore, as the size of the shear panel decreases and it approaches to the middle point of the frame, its desirable properties increase. Generally, the shear panel sizes, in which $l / L-h / H$ ratios vary from $10 \%-10 \%$ to $30 \%-30 \%$, have more effect on the behavior of CBFSPs and EBFSPs. On average, the small sizes of shear panels dissipate $85 \%$ of the induced seismic energy, which is a significant quantity.

\subsubsection{3-story buildings}

Considering the optimum cases of the previous sections, the 3-story models, as shown in Table 5, were analyzed nonlinearly. As seen in Figure 14, both sizes of the

Table 5. The considered 3-story models for nonlinear dynamic analysis.

\begin{tabular}{ccccc}
\hline \multirow{4}{*}{$L / H>1$} & Name & $\begin{array}{c}\boldsymbol{l} / \boldsymbol{L}-\boldsymbol{h} / \boldsymbol{H} \\
(\mathbf{\%})\end{array}$ & $\begin{array}{c}\boldsymbol{a}-\boldsymbol{b} \\
(\mathbf{m})\end{array}$ \\
\hline \multirow{4}{*}{ CBFSP } & & SP21 & $10-10$ & $2-1.4$ \\
& & SP22 & $30-30$ & $2-1.4$ \\
& \multirow{2}{*}{ EBFSP } & SP23 & $10-10$ & $2-1.4$ \\
& & SP24 & $30-30$ & $2-1.4$ \\
\hline
\end{tabular}

shear panel reduce the nonlinear maximum displacement along with maximum base shear with respect to the moment resisting frame. Moreover, SP21, SP22, SP23, and SP24 have approximately the same amounts of energy dissipation capacity. It is concluded that in nonlinear behavior region, $l / L-h / H$ of $30 \%-30 \%$ is relatively more effective than $10 \%-10 \%$.

\section{Seismic performance factors}

\subsection{Finite element models}

In this study, one span 1-, 3-, 6-, and 9-story CBFSPs, and EBFSPs were modeled. The respective values of the span length and story height were $5 \mathrm{~m}$ and $3 \mathrm{~m}$. Material nonlinearity of the members was considered using distributed plasticity concept. Regarding the strip modeling, steel shear panels were created by tension-only truss elements (Figure 1). As mentioned in Section 2.1, nonlinear behavior of the strips was tri-linear by $3 \%$ strain-hardening and $2 \%$ softening (Figure 2(a)). Considering von Mises yielding criteria, all of the other members were modeled by beam-column elements, in which elastic-perfectly plastic nonlinear behavior was considered for them. Table 6 contains the assigned sections to the members along with the values of fundamental periods. Considering $P-\Delta$ effects, the models were analyzed by nonlinear static procedure (i.e., pushover) for a target displacement resulted by $3 \%$ rotation of the base of the columns. This value of rotation was selected in a way that rotation angle in all plastic hinges of the frame was less than the proposed values of AISC341.

\subsection{Over-strength, deflection amplification, and response modification factors}

In fact, the induced forces of severe ground motions are much greater than what is recommended in the design codes. Therefore, the structures will have nonlinear behavior during the design earthquake events. Nowadays, due to this fact that the members with cyclic inelastic behavior can dissipate the induced seismic energy, the buildings are designed for reduced lateral seismic loads. Indeed, by reduction of the design earthquake loads, some of the predetermined parts of the buildings are considered to be fuses, which will absorb the input energy and, hence, the other members remain elastic. This designing procedure causes increase in the lateral displacement of the buildings, which should be tolerated by implementation of appropriate structural details. Thus, by pushover curve (Figure 15) and the following definitions, the required parameters for design of the buildings are calculated.

Figure 15 shows a pushover curve in which the actual response is idealized by a bilinear response curve. In this diagram, ordinate and abscissa illustrate the design base shear coefficient $(C)$ and lateral 

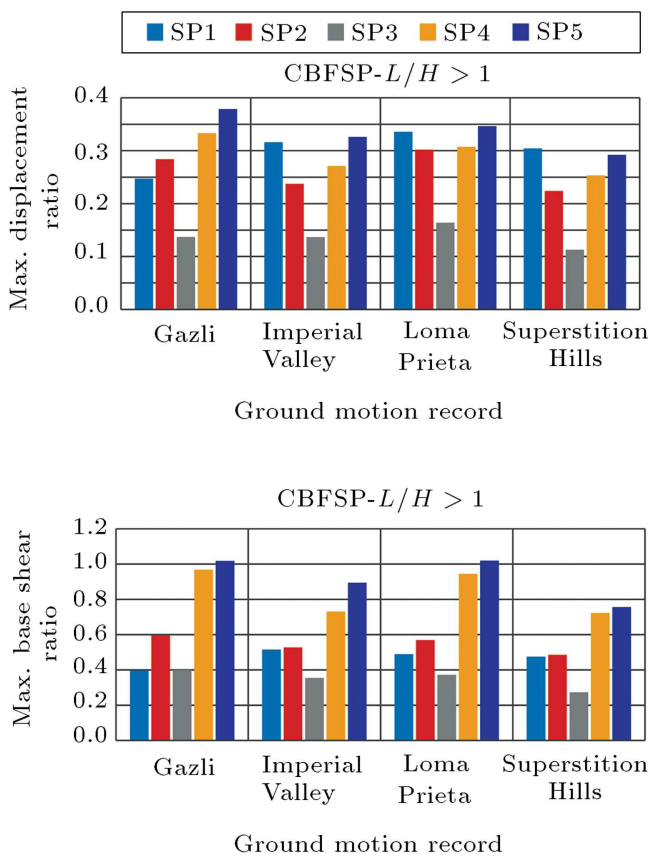

CBFSP- $L / H>1$

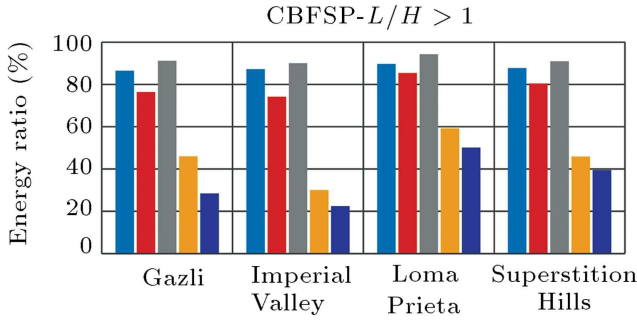

Ground motion record

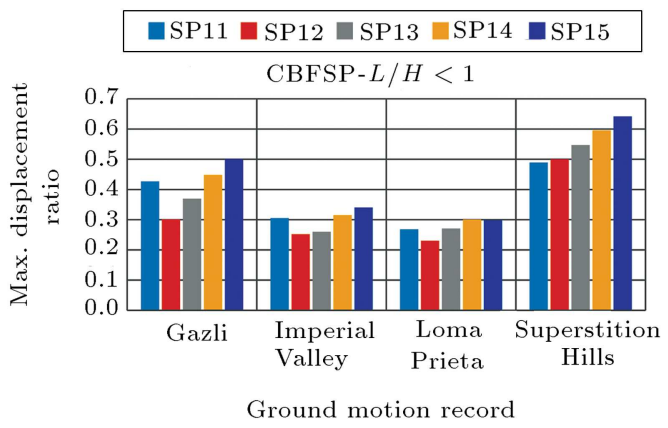

(a)

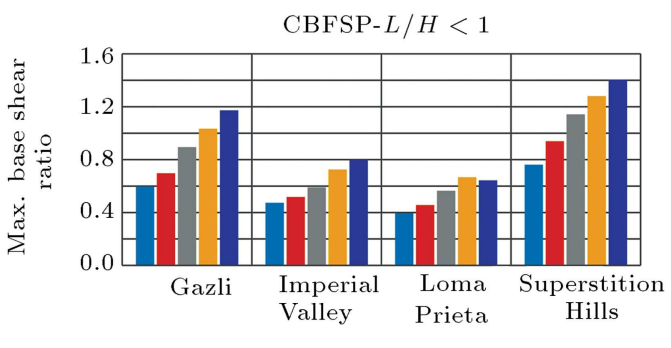

Ground motion record

(b)

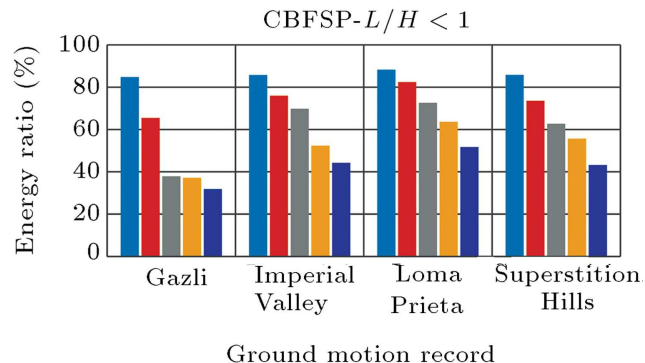

(c)

Figure 12. Evaluation of nonlinear behavior of 1-story CBFSP: (a) Maximum displacement ratio; (b) maximum base shear ratio; and (c) energy ratio.

Table 6. Properties of the building models.

\begin{tabular}{|c|c|c|c|c|c|c|c|c|}
\hline & \multirow[b]{2}{*}{ Story } & \multirow{2}{*}{$\begin{array}{c}\text { 1-story } \\
1\end{array}$} & \multirow{2}{*}{$\begin{array}{c}3 \text {-story } \\
1-2-3\end{array}$} & \multicolumn{2}{|c|}{ 6-story } & \multicolumn{3}{|c|}{ 9-story } \\
\hline & & & & $1-2-3$ & $4-5-6$ & $1-2-3$ & $4-5-6$ & $7-8-9$ \\
\hline \multirow{5}{*}{ CBFSP } & Beam & IPE140 & IPE220 & IPB200 & IPB180 & IPB220 & IPB200 & IPB180 \\
\hline & Column & IPE200 & IPE270 & IPB300 & IPB280 & IPB340 & IPB320 & IPB300 \\
\hline & Brace & IPE160 & IPE220 & IPB200 & IPB180 & IPB220 & IPB200 & IPB180 \\
\hline & Boundary element & IPE120 & IPE120 & IPB120 & IPB120 & IPB120 & IPB120 & IPB120 \\
\hline & Fundamental period (s) & 0.23 & 0.33 & \multicolumn{2}{|c|}{0.42} & \multicolumn{3}{|c|}{0.59} \\
\hline \multirow{7}{*}{ EBFSP } & Beam & IPE200 & IPE220 & IPB220 & IPB200 & IPB220 & IPB200 & IPB180 \\
\hline & Column & IPE200 & IPE270 & IPB300 & IPB280 & IPB340 & IPB320 & IPB300 \\
\hline & Brace & IPE200 & IPE220 & IPB220 & IPB200 & IPB220 & IPB200 & IPB180 \\
\hline & Shear link & IPE100 & IPE120 & IPB160 & IPB140 & IPB180 & IPB160 & IPB140 \\
\hline & Boundary element & IPE120 & IPE120 & IPB120 & IPB120 & IPB120 & IPB120 & IPB120 \\
\hline & Fundamental period $(\mathrm{s})$ & 0.23 & 0.42 & \multicolumn{2}{|c|}{0.49} & \multicolumn{3}{|c|}{0.68} \\
\hline & Thickness of shear panel (mm) & 0.1 & 0.25 & 0.6 & 0.3 & 0.95 & 0.75 & 0.35 \\
\hline
\end{tabular}



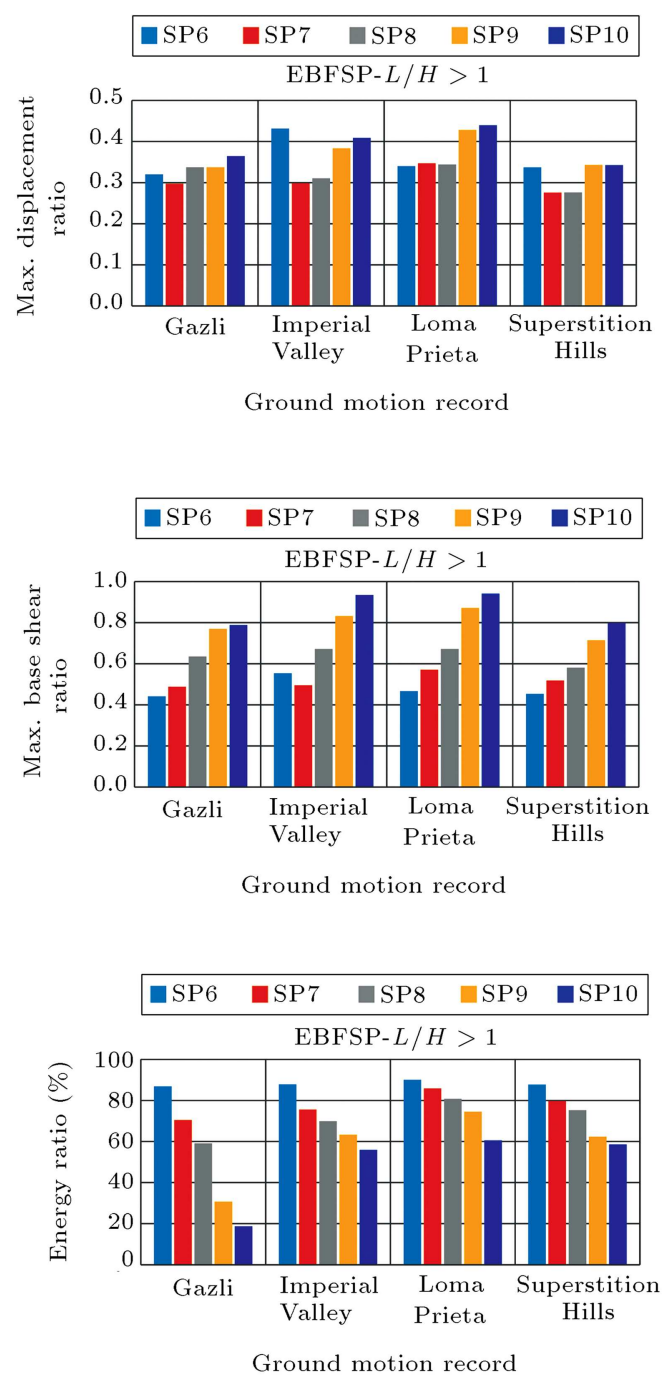

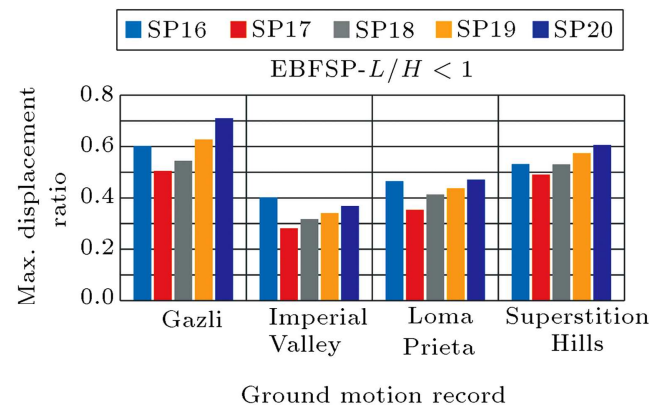

(a)

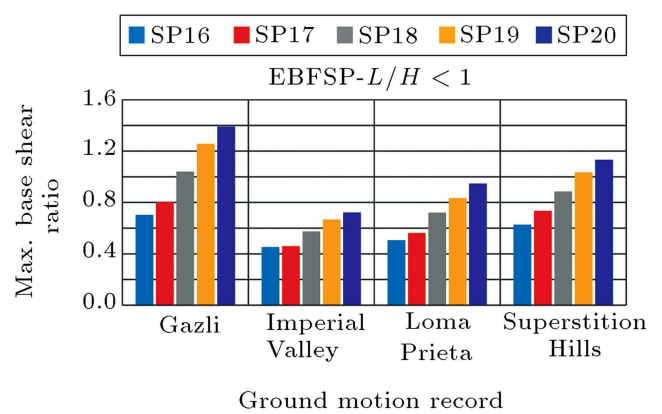

(b)

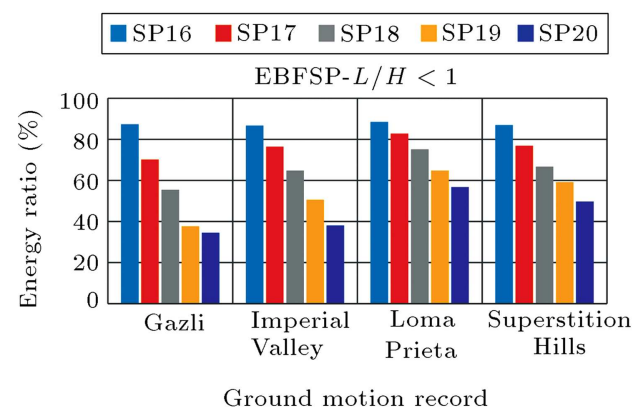

(c)

: (a) Maximum displacement ratio; (b) maximum base

strain-hardening, selection of typical sections for the members, non-seismic loading combinations, etc. cause that structural systems to have over-strength. Overstrength factor $\left(\Omega_{0}\right)$ gives the reserved strength of the system, which exists between the yielding and LRFD base shear coefficients. This factor can be obtained by Eq. (5):

$$
\Omega_{0}=\frac{C_{y}}{C_{s}}=\frac{\delta_{y}}{\delta_{s}}
$$

where $C_{y}$ is yielding base shear coefficient of the building; $C_{s}$, LRFD base shear coefficient of the building; and $\delta_{s}$, lateral displacement of the building corresponding to $C_{s}$. As previously mentioned, by designing the buildings for reduced seismic loads, their lateral displacement increases. Typically, based on common design codes, lateral displacement of the buildings is calculated by elastic analysis. Next, for estimation of the actual inelastic displacement using

where $\delta_{u}$ is the ultimate displacement of the building in plastic behavior range and $\delta_{y}$ is yielding displacement of the building. Some factors such as redistribution of internal forces, additional strength of materials, 


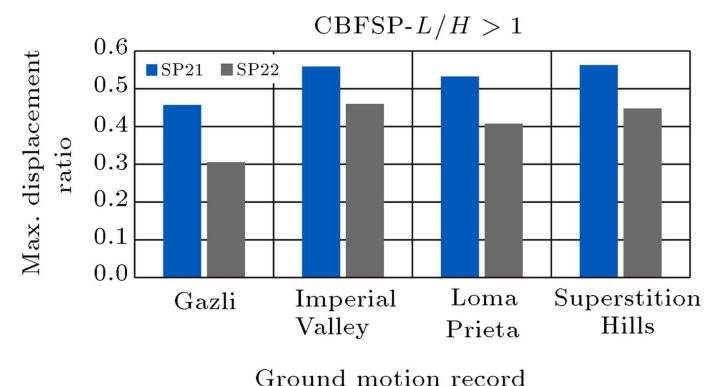

(a)

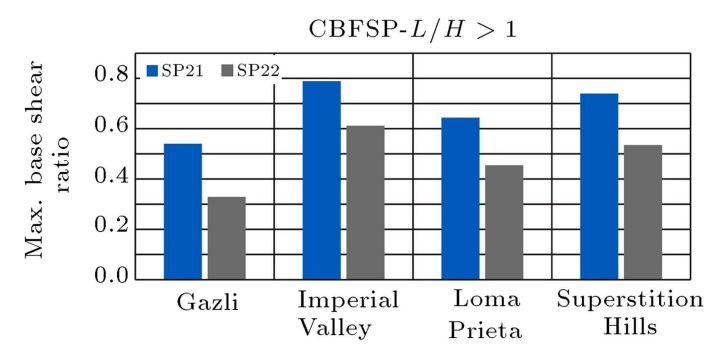

Ground motion record

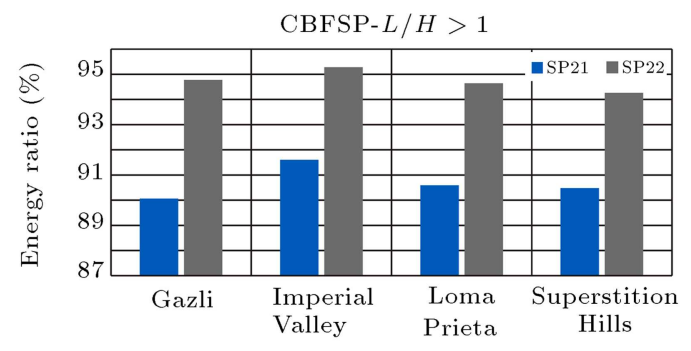

Ground motion record

(b)

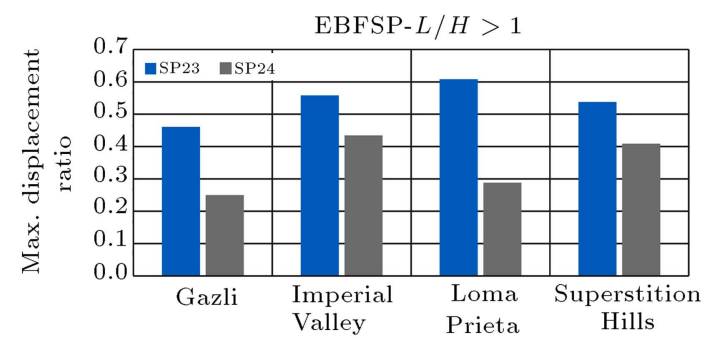

Ground motion record

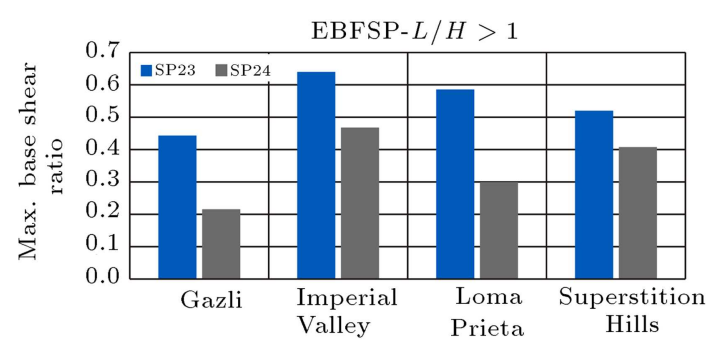

Ground motion record

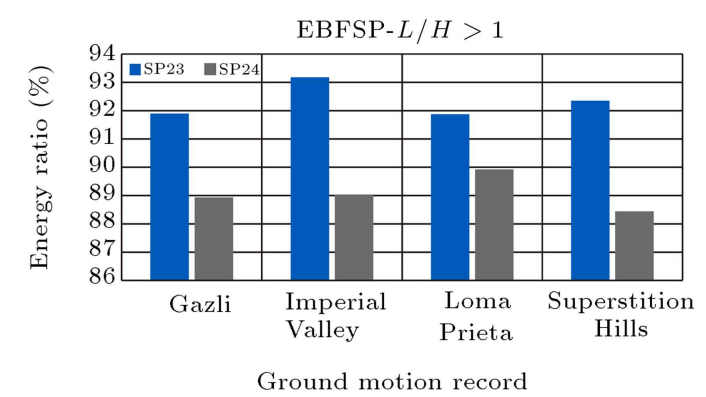

(c)

Figure 14. Evaluation of nonlinear behavior of 3-story CBFSP and EBFSP: (a) Maximum displacement ratio; (b) maximum base shear ratio; and (c) energy ratio.

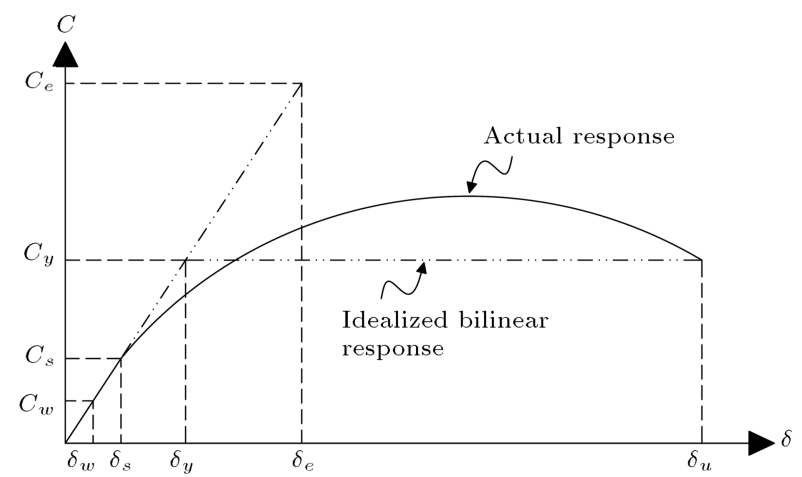

Figure 15. Definition of the seismic performance factors using pushover curve.

the elastic one, deflection amplification factor $\left(C_{d s}\right.$ or $\left.C_{d w}\right)$ is used. Deflection amplification factor for LRFD procedure $\left(C_{d s}\right)$ can be estimated by Eq. (6):

$$
C_{d s}=\frac{\delta_{u}}{\delta_{s}}=\mu . \Omega_{0}
$$

where the parameters are as previously defined. The difference between the ASD and LRFD procedures is expressed by the allowable stress factor $(Y)$ which has a value of 1.4 to 1.7. Eq. (7) gives the value of $Y$ :

$$
Y=\frac{R_{w}}{R_{u}}=\frac{C_{s}}{C_{w}}=\frac{\delta_{s}}{\delta_{w}}=1.4,
$$

where $R_{w}$ is ASD response modification factor; $R_{u}$, LRFD response modification factor; $C_{w}$, ASD base shear coefficient; $\delta_{w}$, lateral displacement of the building corresponding to $C_{w}$. In this study, a value of 1.4 was used for $Y$. Thus, deflection amplification factor for ASD procedure $\left(C_{d w}\right)$ is achieved by Eq. (8):

$$
C_{d w}=\frac{\delta_{u}}{\delta_{w}}=\mu \cdot \Omega_{0} . Y .
$$

Ductility reduction factor $\left(R_{\mu}\right)$ causes reduction in the seismic loads from elastic level to yielding level. In fact, by adopting ductility, the building has a capacity for dissipating seismic energy. $R_{\mu}$ is defined by Eq. (9):

$$
R_{\mu}=\frac{C_{e}}{C_{y}} .
$$


Many researchers have suggested relations for calculation of ductility reduction factor. Based on the performed investigations, $R_{\mu}$ is a function of ductility, fundamental period, nonlinear behavior of the members, and ground motion characteristics. Four different proposed equations were used in this paper as the following:

1. Newmark-Hall [16]:

$$
\begin{aligned}
& T \leq 0.03 \mathrm{sec} \Rightarrow R_{\mu}=1 \\
& 0.12 \mathrm{sec} \leq T \leq 0.5 \mathrm{sec} \Rightarrow R_{\mu}=\sqrt{2 \mu-1} \\
& T \geq 1 \mathrm{sec} \Rightarrow R_{\mu}=\mu
\end{aligned}
$$

where $T$ is the fundamental period and $\mu$ represents ductility coefficient.

2. Riddell-Hidalgo-Cruz [17]:

$$
\begin{aligned}
& 0 \leq T \leq T_{0} \Rightarrow R_{\mu}=1+\left(R_{\max }-1\right) \frac{T}{T_{0}}, \\
& T \geq T_{0} \Rightarrow R_{\mu}=R_{\max }
\end{aligned}
$$

where values of $R_{\max }$ and $T_{0}$ are dependent on $\mu$.

3. Nassar-Krawinkler [18]:

$$
\begin{aligned}
& R_{\mu}=[c(\mu-1)+1]^{\left(\frac{1}{c}\right)}, \quad c=\frac{T^{a}}{1+T^{a}}+\frac{b}{T}, \\
& \alpha=3 \% \Rightarrow a=0.975, \quad b=0.36,
\end{aligned}
$$

where $\alpha$ is strain-hardening slope, which, in this paper, equals $3 \%$; $a$ and $b$ are dependent on $\alpha$; and the other parameters are as previously defined.

4. Fajfar [19]:

$$
\begin{aligned}
& T<T_{c}=T_{s}=\frac{S_{D 1}}{S_{D S}} \Rightarrow R_{\mu}=(\mu-1) \frac{T}{T_{c}}+1, \\
& T \geq T_{c} \Rightarrow R_{\mu}=\mu,
\end{aligned}
$$

where $T_{c}$ is the characteristic of the ground motion, which, in this study, equals $0.53 \mathrm{~s} ; S_{D 1}$, design, $5 \%$ damped, spectral response acceleration parameter at a period of $1 \mathrm{~s}$; and $S_{D S}$, design, $5 \%$ damped, spectral response acceleration parameter at short periods. Finally, response modification factors ( $R_{u}$ and $R_{w}$ ) reduce the base shear coefficient from $C_{e}$ to $C_{s}$ in LRFD and from $C_{e}$ to $C_{w}$ in ASD. Eqs. (14) and (15) show definitions of $R_{u}$ (i.e., response modification factor for LRFD) and $R_{w}$ (i.e., response modification factor for $\mathrm{ASD}$ ), respectively:

$$
\begin{aligned}
& R_{u}=\frac{C_{e}}{C_{s}}=\frac{C_{e}}{C_{y}} \cdot \frac{C_{y}}{C_{s}}=R_{\mu} \cdot \Omega_{0}, \\
& R_{w}=\frac{C_{e}}{C_{w}}=\frac{C_{e}}{C_{y}} \cdot \frac{C_{y}}{C_{s}} \cdot \frac{C_{s}}{C_{w}}=R_{\mu} \cdot \Omega_{0} \cdot Y .
\end{aligned}
$$

\begin{tabular}{|c|c|c|c|c|c|c|c|c|}
\hline & \multicolumn{4}{|c|}{ CBFSP } & \multicolumn{4}{|c|}{ EBFSP } \\
\hline & 1-story & 3-story & 6-story & 9-story & 1-story & 3-story & 6-story & 9-story \\
\hline$\mu$ & 3.60 & 3.38 & 3.02 & 2.93 & 4.29 & 4.03 & 3.80 & 3.54 \\
\hline$\Omega_{0}$ & 6.90 & 6.10 & 5.40 & 3.80 & 5.60 & 4.20 & 4.00 & 3.60 \\
\hline$C_{d s}$ & 24.84 & 20.59 & 16.29 & 11.15 & 24.00 & 16.93 & 15.21 & 12.73 \\
\hline$C_{d w}$ & 34.78 & 28.82 & 22.81 & 15.61 & 33.60 & 23.70 & 21.30 & 17.83 \\
\hline$R_{\mu}$ (Newmark-Hall) & 2.49 & 2.40 & 2.24 & 2.22 & 2.75 & 2.66 & 2.57 & 2.54 \\
\hline$R_{\mu}$ (Nassar-Krawinkler) & 2.70 & 2.94 & 2.85 & 2.96 & 3.03 & 3.71 & 3.68 & 3.68 \\
\hline$R_{\mu}$ (Fajfar) & 2.13 & 2.48 & 2.60 & 2.90 & 2.43 & 3.40 & 3.59 & 3.50 \\
\hline$R_{\mu}$ (Riddell-Hidalgo-Cruz) & 3.30 & 3.40 & 3.00 & 2.90 & 3.30 & 4.00 & 3.80 & 3.50 \\
\hline$R_{u}($ Newmark-Hall $)$ & 17.18 & 14.63 & 12.12 & 8.44 & 15.41 & 11.16 & 10.28 & 9.14 \\
\hline$R_{w}($ Newmark-Hall $)$ & 24.05 & 20.48 & 16.96 & 11.81 & 21.57 & 15.62 & 14.39 & 12.80 \\
\hline$R_{u}$ (Nassar-Krawinkler) & 18.64 & 17.92 & 15.39 & 11.26 & 16.96 & 15.58 & 14.74 & 13.24 \\
\hline$R_{w}$ (Nassar-Krawinkler) & 26.10 & 25.08 & 21.55 & 15.77 & 23.75 & 21.81 & 20.63 & 18.53 \\
\hline$R_{u}$ (Fajfar) & 14.69 & 15.12 & 14.03 & 11.02 & 13.58 & 14.28 & 14.37 & 12.60 \\
\hline$R_{w}$ (Fajfar) & 20.56 & 21.17 & 19.64 & 15.43 & 19.02 & 20.00 & 20.11 & 17.64 \\
\hline$R_{u}$ (Riddell-Hidalgo-Cruz) & 22.77 & 20.74 & 16.20 & 11.02 & 18.48 & 16.80 & 15.20 & 12.60 \\
\hline$R_{w}$ (Riddell-Hidalgo-Cruz) & 31.88 & 29.04 & 22.68 & 15.43 & 25.87 & 23.52 & 21.28 & 17.64 \\
\hline
\end{tabular}

Considering the above-mentioned definitions and nonlinear static analysis of the models, seismic performance factors of CBFSPs and EBFSPs were evaluated using the resulted pushover curves (Table 7). In this paper, idealized bilinear response of the pushover

Table 7. Seismic performance factors. 

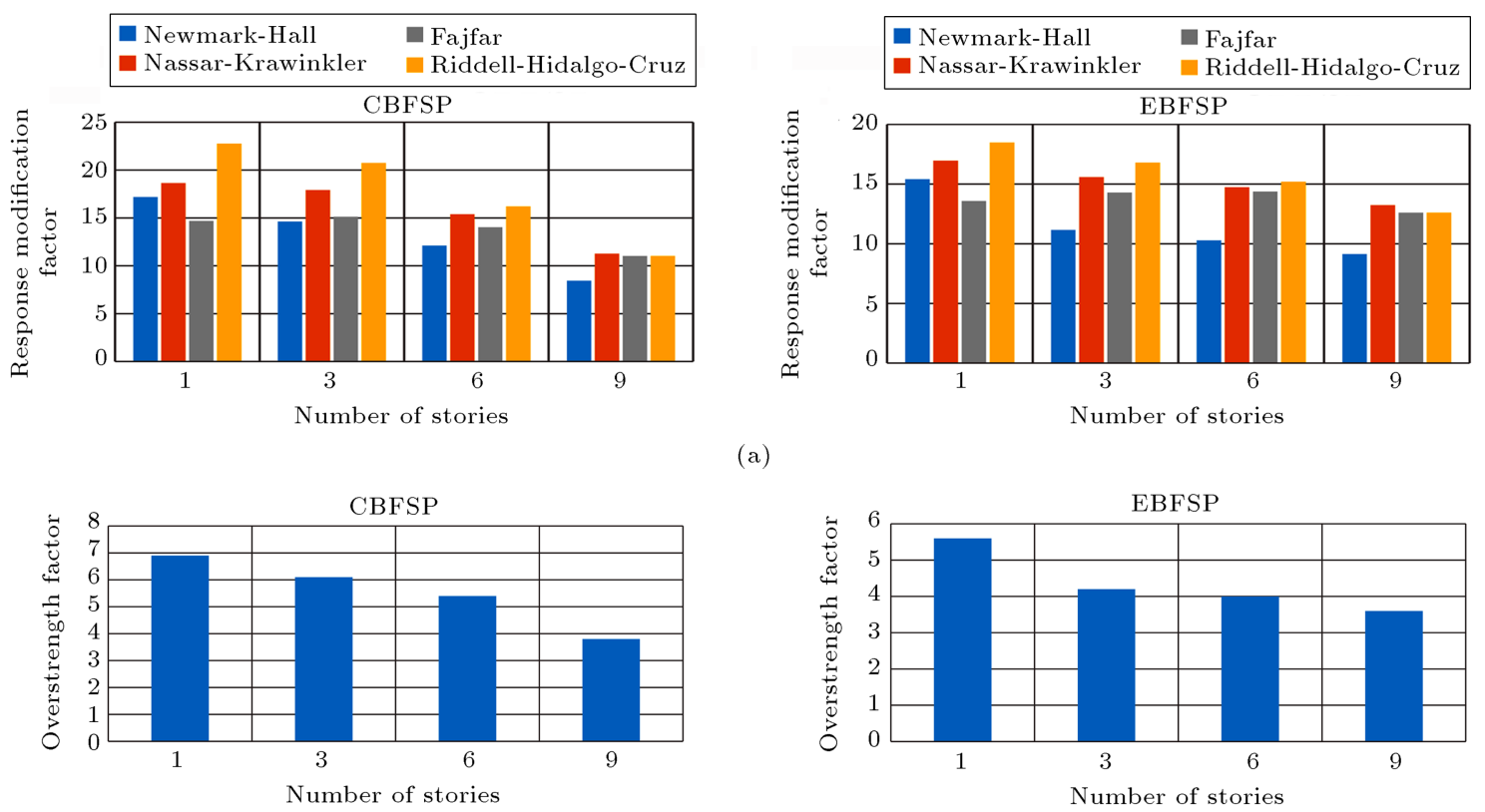

(b)
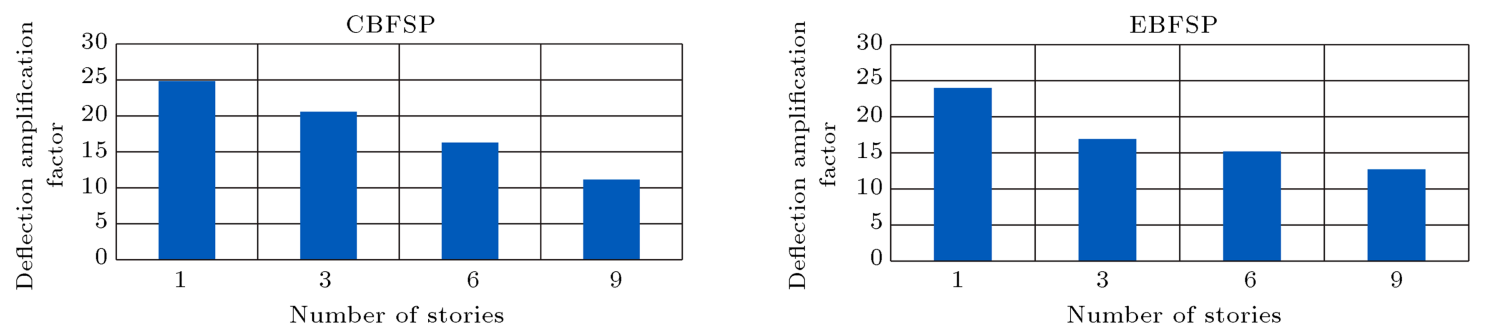

(c)

Figure 16. Comparison of seismic performance factors versus number of stories for CBFSP and EBFSP: (a) Response modification factor; (b) over-strength factor; and (c) deflection amplification factor.

curves was obtained following the FEMA 356 procedure.

As shown in Figure 16, it is concluded that $R_{u}$, $\Omega_{0}$, and $C_{d s}$ are functions of the number of stories. By increasing the number of stories, which is equivalent to the increase in fundamental period, the values of the aforementioned parameters decrease. By averaging the obtained values for the seismic performance factors, the following values are achieved:

$$
\begin{aligned}
& \text { CBFSP : } \Omega_{0}=5.6, C_{d s}=18.2, R_{u}=13.1, \\
& \text { EBFSP : } \Omega_{0}=4.4, C_{d s}=17.2, R_{u}=11.5 .
\end{aligned}
$$

It should be noted that in averaging values of $R_{u}$, only the Newmark-Hall equation was considered. This was due to this fact that the obtained values of $R_{u}$ by Newmark-Hall equation were less than those of the other equations, which led to increase in safety in the design of CBFSPs and EBFSPs. It is worth noting that combination of braced frame and shear panel system causes increase in over-strength and lateral stiffness. Moreover, reduction of yield displacement, owing to high lateral stiffness, is the cause of increase in ductility factor (Eq. (4)) along with ductility reduction factor (Eq. (10)). Eventually, simultaneous increase in $R_{\mu}$ and $\Omega_{0}$ is the reason for achievement to high values of response modification factor for low-rise buildings. Furthermore, it should be noted that in this study, seismic performance factors were calculated only for 1-, 3-, 6-, and 9-story models without non-structural elements and considering Figure 16, which depicts decreasing trend of these factors against the number of story, it can be concluded that the average value of these factors will be lower. This result has been achieved by Maheri and Akbari [20], Asgarian and Shokrgozar [21], and Mahmoudi and Zaree [22]. It is expected that by investigation of high-rise models, the minimum value of $R_{u}$ will be equal to 8 , which has been proposed by ASCE7 for special steel plate shear walls.

\subsection{Fundamental period}

In common design codes, it is needed to estimate the fundamental period of the structure for advancement of the designing procedure. Therefore, the objective of this section is to present an empirical equation for 


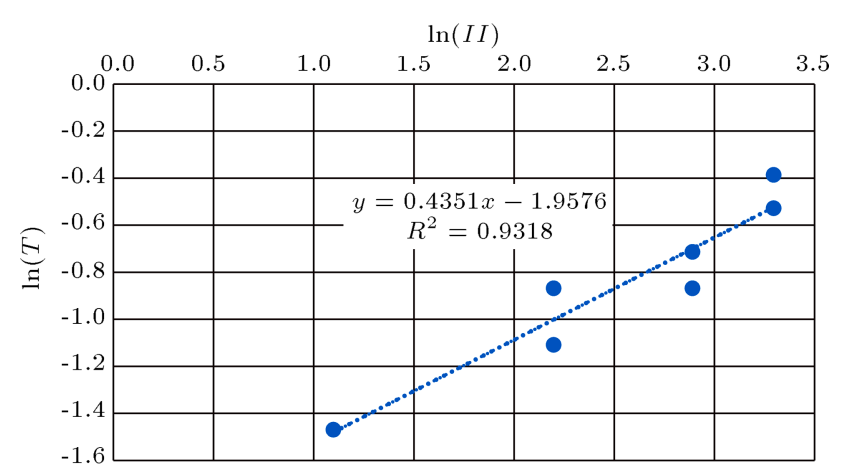

Figure 17. Linear regression of fundamental period vs. building height.

CBFSP and EBFSP as new seismic resisting systems. For this purpose, an equation in which fundamental period $(T)$ is proportional to the height of the building $(H)$ was considered. As seen in Eq. (16), by applying the natural $\log$ on both sides of the considered equation, a linear relationship is ultimately achieved:

$$
\begin{aligned}
T & =\alpha H^{\beta} \Rightarrow \ln (T)=\ln (\alpha)+\beta \ln (H) \\
& \Rightarrow y=\beta x+\ln (\alpha) .
\end{aligned}
$$

Considering the fundamental periods of 1-, 3-, 6-, and 9-story CBFSPs and EBFSPs versus their corresponding height, a linear regression was performed to calculate the unknown parameters of $\alpha$ and $\beta$. Figure 17 shows the resulted equation along with its $R$-squared value, which illustrates its good precision. Based on the computed parameters, it is concluded that for these types of structural systems, the respective values of $\alpha$ and $\beta$ are 0.14 and 0.44 .

\section{Conclusions}

The objective of this paper was to present a parametric study and quantification of seismic performance factors for braced steel shear panels (i.e., CBFSP and EBFSP). Using linear static along with nonlinear dynamic analyses of 1- and 3-story finite element models, the optimum size and location of the shear panel were investigated. Furthermore, over-strength, deflection amplification, and response modification factors of the new seismic resisting systems were evaluated by pushover analysis of 1-, 3-, 6-, and 9-story models. Finally, an equation for calculation of fundamental period of CBFSPs and EBFSPs was proposed by linear regression procedure. The most highlighted results of this study are as follow:

- By increasing the shear panel dimensions, the lateral stiffness of the CBFSPs and EBFSPs decrease. Among the examined dimensions, $l / L=h / H=$ $10 \%$ has the maximum lateral stiffness;

- For both CBFSPs and EBFSPs, to achieve the maximum lateral stiffness till $l / L=h / H=30 \%$, the ratios of HBE to span length and VBE to story height should be equal. However, by increasing the size of the shear panel, for $L / H>1, h / H$ is $10 \%$ higher than $l / L$ and for $L / H<1$, this relationship is vice versa. In other words, considering the results of the two previous sentences, it can be generally said that, if $L / H>1 \Rightarrow L / H \geq l / h$ and if $L / H<1 \Rightarrow L / H \leq l / h$;

- The best location for the shear panel is the middle point of the frame or, to some extent, upper (i.e., up to approximately $25 \%$ higher than mid-height of the story);

- Based on the nonlinear time-history analyses, it was concluded that by decreasing the dimensions of the shear panel, generally, the maximum displacement and maximum base shear decrease and the dissipated energy increases. Moreover, in nonlinear behavior region, $l / L=h / H=30 \%$ is more effective than $l / L=h / H=10 \%$;

- In the range of the studied models, the empirical values for seismic performance factors are as the following:

$$
\begin{aligned}
& \text { CBFSP : } \Omega_{0}=5.6, C_{d s}=18.2, R_{u}=13.1, \\
& \operatorname{EBFSP}: \Omega_{0}=4.4, C_{d s}=17.2, R_{u}=11.5
\end{aligned}
$$

- For estimation of the fundamental period of CBFSP and EBFSP, an equation in the form of $T=$ $0.14 H^{0.44}$ can be used.

\section{References}

1. Timler, P., Ventura, C.E., Prion, H. and Anjam, R. "Experimental and analytical studies of steel plate shear walls as applied to the design of tall buildings", The Structural Design of Tall and Special Buildings, 7(3), pp. 233-249 (1998).

2. Youssef, N., Wilkerson, R., Fischer, K. and Tunick, D. "Seismic performance of a 55-story steel plate shear wall", The Structural Design of Tall and Special Buildings, 19(1-2), pp. 139-165 (2010).

3. Kang, TH.K., Martin, R.D., Park, H.G., Wilkerson, R. and Youssef, N. "Tall building with steel plate shear walls subject to load reversal", The Structural Design of Tall and Special Buildings, 22(6), pp. 500520 (2011).

4. Xue, M. and Lu, L.W. "Interaction of infilled steel shear wall panels with surrounding frame members", Proceedings of the Structural Stability Research Council Annual Technical Session, Bethlehem, PA, pp. 339354 (1994).

5. Pirmoz, A. "Beam-attached steel plate shear walls", The Structural Design of Tall and Special Buildings, 21(12), pp. 879-895 (2010). 
6. Kurata, M., Leon, R.T., DesRoches, R. and Nakashima, M. "Steel plate shear wall with tensionbracing for seismic rehabilitation of steel frames", Journal of Constructional Steel Research, 71(April 2012), pp. 92-103 (2012).

7. Neal, J. and Qu, B. "Steel plate shear walls with controlled infill tension fields", Proceedings of the Structures Congress, Las Vegas, Nevada, United States, pp. 3018-3028 (2011).

8. De Matteis, G., Brando, G. and Mazzolani, F.M. "Hysteretic behaviour of bracing-type pure aluminium shear panels by experimental tests", Earthquake Engineering and Structural Dynamics, 40(10), pp. 11431162 (2011).

9. Akbari Hamed, A. "Design, modeling and investigation of seismic behavior of bracing type steel shear panels", PhD Dissertation (in Persian), Civil Engineering Department, Sharif University of Technology, Tehran, Iran (2014).

10. Tajammolian, H. and Mofid, M. "On the characteristics and design of yielding elements used in steel-braced framed structures", The Structural Design of Tall and Special Buildings, 22(2), pp. 179-191 (2010).

11. Mazzolani, F.M. and Piluso, V. "Plastic design of seismic resistant steel frames", Earthquake Engineering and Structural Dynamics, 26(2), pp. 167-191 (1997).

12. Akbari Hamed, A. and Mofid, M. "On the plastic analysis of concentrically braced frames with shear panel, obtaining predetermined collapse mechanism", The Structural Design of Tall and Special Buildings, 24(5), pp. 366-395 (2015).

13. Abell, M. and Napier, J. "Fast nonlinear analysis", Online available at: https://wiki.csiamerica. $\mathrm{com} /$ pages/viewpage. action?pageId=9536464 (2014).

14. Akbari Hamed, A. and Mofid, M. "On the experimental and numerical study of braced steel shear panels", The Structural Design of Tall and Special Buildings, 24(14), pp. 853-872 (2015).

15. Shishkin, J.J., Driver, R.G. and Grondin, G.Y. "Analysis of steel plate shear walls using the modified strip model", Structural Engineering Report No. 261, Department of Civil and Environmental Engineering, University of Alberta, Edmonton, Alberta (2005).
16. Newmark, N.M. and Hall, W.J. "Earthquake spectra and design", A Monograph Pub by the Earthquake Engineering Research Center, Berkeley, California (1982).

17. Riddell, R., Hidalgo, P. and Cruz, E. "Response modification factors for earthquake resistant design of short period buildings", Earthquake Spectra, 5(3), pp. 571-590 (1989).

18. Nassar, A.A. and Krawinkler, H. "Seismic demands for SDOF and MDOF systems", The John A. Blume Earthquake Engineering Center, Report No. 95, Stanford University, Stanford, California (1991).

19. Fajfar, P. "Structural analysis in earthquake engineering - a breakthrough of simplified nonlinear methods", Proceedings of 12th European Conference on Earthquake Engineering, London, UK, Paper No. 843 (2002).

20. Maheri, M.R. and Akbari, R. "Seismic behaviour factor, R, for steel X-braced and knee-braced RC buildings", Engineering Structures, 25(12), pp. 15051513 (2003).

21. Asgarian, B. and Shokrgozar, H.R. "BRBF response modification factor", Journal of Constructional Steel Research, 65(2), pp. 290-298 (2009).

22. Mahmoudi, M. and Zaree, M. "Evaluating response modification factors of concentrically braced steel frames", Journal of Constructional Steel Research, 66(10), pp. 1196-1204 (2010).

\section{Biographies}

Arash Akbari Hamed is an Assistant Professor in Department of Civil Engineering at Sahand University of Technology. He received his BSc and MSc degrees in Structural Engineering from the University of Tabriz. Moreover, he received his Structural Engineering PhD degree from Sharif University of Technology. His research interests include design, passive control, and rehabilitation of steel structures.

Massood Mofid is a Professor in Department of Civil Engineering at Sharif University of Technology. He received his BSc degree from the University of Tehran. Moreover, he received his $\mathrm{MSc}$ and $\mathrm{PhD}$ degrees from Rice University. 